\title{
The protective roles of tea tree oil extracts in bovine mammary epithelial cells and polymorphonuclear leukocytes
}

\author{
Kang Zhan ${ }^{1 \dagger}$, Tianyu Yang ${ }^{1 \dagger}$, Baobao Feng ${ }^{1}$, Xinyu Zhu², Yinyin Chen ${ }^{1}$, Yongjiu Huo ${ }^{1}$ and Guoqi Zhao ${ }^{1 *}$ (D)
}

\begin{abstract}
Background: Tea tree oil (TTO) plays an important role in antibacterial activity and alleviating the inflammatory responses. Bovine mammary epithelium and polymorphonuclear leukocytes (PMNL) can actively respond to bovine mastitis infection. However, regulatory effects of $T \mathrm{TO}$ extracts on the innate immune response of bovine mammary epithelial cells (BMECs) and PMNL remain not reported. Therefore, aim of the study was to evaluate the effects of TTO extracts on the mRNA levels of the genes involved in the innate immune response of BMECs and PMNL.

Results: Our results demonstrated that addition of $0.025 \%$ and $0.05 \% \pi \mathrm{T}$ increased the proliferation of BMECs, and significantly enhanced $(P<0.05)$ the viability of BMECs exposed to Staphylococcus aureus (S. aureus). An inhibitory effect was observed against the growth of $S$. aureus by TTO incubation. The $0.05 \%$ TTO reduced S. aureus biofilm formation, association and invasion of $S$. aureus to BMECS, and changed the morphological and structural features of $S$. aureus. The proinflammatory cytokines IL-1 $\beta, I L-6$, and TNF-a were decreased $(P<0.001)$ by the incubation of TTO. Interestingly, the expression of IL-8 known for PMNL chemotactic function was elevated $(P<0.05)$ by $0.05 \%$ TTO treatment. Consistently, 0.05\% TTO increased the migration of PMNL in S. aureus-exposed BMECs when compared with $S$. aureus treatment alone $(P<0.05)$. In addition, PMNL incubated with $0.05 \%$ TTO decreased the levels of NFKB inhibitor alpha (NFKBIA) and TNF-a.
\end{abstract}

Conclusions: Our results indicate that use of TTO can relieve the BMECS pro-inflammatory response caused by $S$. aureus and promote the migration of PMNL to mount the innate immune responses, and it may be novel strategy for the treatment of bovine mastitis caused by S. aureus.

Keywords: Bovine mammary epithelial cells, Mastitis, PMNL, Staphylococcus aureus, Tea tree oil

\section{Introduction}

Bovine mastitis, an inflammation of mammary gland, is a serious infectious disease involved in the infection with a pathogen, such as Staphylococcus aureus (S. aureus), Escherichia coli, and Streptococcus [1], and results in decreased milk quality [2] and economic losses [3]. Bovine mastitis is divided into clinical and subclinical mastitis.

\footnotetext{
* Correspondence: gqzhao@yzu.edu.cn

${ }^{\dagger}$ Kang Zhan and Tianyu Yang contributed equally to this work.

${ }^{1}$ Institute of Animal Culture Collection and Application, College of Animal Science and Technology, Yangzhou University, Yangzhou 225009, China

Full list of author information is available at the end of the article
}

Clinical mastitis is readily observed and easily detected by abnormal milk secretions, whereas subclinical mastitis is asymptomatic and difficult to be observed and is diagnosed by the reservoir of pathogen infection in milk [4]. Recent investigation showed that $S$. aureus is a major cause of contagious bovine subclinical mastitis [5]. However, the emergence of antibiotic resistant strains of $S$. aureus known for methicillin-resistant $S$. aureus (MRSA) is a serious health hazard around the world [6], and MRSA infections have been observed in cases of bovine mastitis [7]. 
Some antibiotics to cure the clinical bovine mastitis have been widely used in the past study. However, many consumer concerns about the development of resistance to antibiotics agents are worried in some developing countries [8]. Furthermore, antibiotics to treat the bovine mastitis triggered by $S$. aureus has poor efficacy due to a low cure rate in clinical mastitis [9]. Importantly, the treatment of bovine mastitis using antibiotics is worried for human health because of the presence of residues of these antibiotics in milk. Therefore, the development of novel, alternative therapies strategies to both inhibit the pathogen and have the capacity to mount the innate immune response to kill the pathogen are urgent need for improving milk quality and human health.

Many plant extracts and essential oils derived from some plants contain secondary metabolites that shows antibacterial activity properties $[10,11]$. Tea tree oil (TTO), an essential oil extracted from the leaves of Melaleuca alternifolia ( $M$. alternifolia), plays an important role in antibacterial activity and anti-inflammatory properties [12]. TTO extract from the leaves of $M$. alternifolia contains the terpinen-4-ol, $\gamma$-terpinene, $\alpha$ terpinene, 1,8-cineole, and $\alpha$-terpineol [13]. The antibacterial activity of TTO primarily depends on its ability to result in increased membrane permeability, and it also disrupts the bacterial cell membrane structures and function $[14,15]$. In addition, previous studies have investigated that innate immune responses play an important role in the resistance to pathogen [16] and improvement of somatic cells in milk [17]. During bovine mastitis, recruitment of circulating blood PMNL to mammary gland for mounting the innate immune responses are critical for alleviating the inflammatory response of bovine mammary epithelial cells (BMECs) and resolution of mastitis [18]. However, to our knowledge, no study has investigated the effects of TTO on the innate immune response of BMECs and PMNL function. We hypothesized that TTO can alleviate the proinflammatory responses of BMECs exposed with $S$. aureus and mount the innate immune responses of BMECs and PMNL.

Therefore, the objectives of this study were to evaluate the effects of TTO extracts on the expression of genes involved in the inflammatory response of BMECs exposed with $S$. aureus, the innate immune response of BMECs and PMNL, and the chemotactic ability of PMNL.

\section{Materials and methods}

\section{Preparation of tea tree oil extracts}

Tea tree essential oil preliminary product were obtained from True Blue Organics (New Zealand). The TTO extract was carried out by Wuxi Chenfang Biotechnology
Co., Ltd. (Wuxi, Jiangsu, China). The oil preliminary product was loaded into reaction still. Then, the nitrogen was added into the reaction still. In addition, reaction still continuously maintains the $0.2 \mathrm{~kg} / \mathrm{cm}^{2}-1 \mathrm{~kg} /$ $\mathrm{cm}^{2}$ pressure at $30-45^{\circ} \mathrm{C}, 45-70{ }^{\circ} \mathrm{C}$, and $70-85^{\circ} \mathrm{C}$ for 1 $\mathrm{h}$, respectively. Oil pump was operated to keep the tea tree essential oils circulating in reaction still. Eventually, the cooling water was used to cool the tubes room temperature. The air compressor and nitrogen turn off, and stopping the essential oils circulating. The TTO extracts were separated using 9790 gas chromatograph fitted with a flame-ionization detector. The samples were injected through the split injection port (50:1) onto a $35 \%$ diphenyl-65\%methylsiloxane polymeride $60 \mathrm{~m} \times$ $0.25 \mathrm{~mm}$ column with a $0.25-\mu \mathrm{m}$ film. The oven temperature was initially $50^{\circ} \mathrm{C}$ for $1 \mathrm{~min}$, and was then increased at $10{ }^{\circ} \mathrm{C} / \mathrm{min}$ to $250^{\circ} \mathrm{C}$ and then held for 9 min. The injector and detector temperatures were maintained at $200{ }^{\circ} \mathrm{C}$ and $300^{\circ} \mathrm{C}$, respectively.

\section{Animals}

This study was carried out in accordance with the principles of Yangzhou University, the Institutional Animal Care and Use Committee (SYXK (Su) IACUC 20120029). All procedures involving the use of live animals was approved by the Institutional Animal Care and Use Committee. Six mid-lactating Holstein cows were used in this study. All cows were free of clinical signs of disease before isolation of polymorphonuclear leukocytes (PMNL). These cows were fed a TMR to meet $100 \%$ of NRC requirements. Cows were milked three times daily at 8:00, 14:00, and 21:00, respectively. The blood (approximately $10 \mathrm{~mL}$ ) was collected by venipuncture of the jugular vein into acid citrate dextrose anti-coagulant (ACD-A) (Solarbio, Shanghai, China) from each cow before the morning feeding. These tubes were slightly inverted to mix, and placed on ice. Blood samples were immediately transported to laboratory and processed within $30 \mathrm{~min}$ of collection.

\section{Cell culture}

Bovine mammary epithelial cells (BMECs) of three midlactating Holstein cows were obtained from the Institute of Animal Culture Collection and Application, Yangzhou University. These bovine mammary tissues were digested by collagenase type I (Invitrogen, Shanghai, China) for 3 $\mathrm{h}$, and cells were filtered by nylon mesh $(75 \mu \mathrm{m})$ to obtain the BMECs. BMECs were seeded in DMEM/F12 medium supplemented with $10 \%$ fetal bovine serum (FBS), $4 \mathrm{~mm} / \mathrm{L}$ glutamine, $1 \times$ insulin, transferrin, sodium selenite $(10 \mu \mathrm{g} / \mathrm{mL}$ insulin, $5.5 \mu \mathrm{g} / \mathrm{mL}$ transferrin, $0.0067 \mu \mathrm{g} / \mathrm{mL}$ sodium selenite, Invitrogen, Shanghai, China), $15 \mathrm{ng} / \mathrm{mL}$ epidermal growth factor (Peprotech, 
Shanghai, China), $1 \mu \mathrm{g} / \mathrm{mL}$ hydrocortisone, and $4 \mu \mathrm{g} / \mathrm{mL}$ prolactin (Sigma-Aldrich, Shanghai, China).

\section{Isolation of PMNL}

PMNL were isolated and obtained as described previously [19] with minor adaptations. Six mid-lactating Holstein cows were used to isolate the PMNL. The venous blood was transferred to $15 \mathrm{~mL}$ sterile tubes containing the $2.2 \mathrm{~mL} \mathrm{ACD}-\mathrm{A}$, gently inverted to mix, and placed on ice. These tubes were centrifuged at $1000 \times g$ at $4{ }^{\circ} \mathrm{C}$ for $20 \mathrm{~min}$, and the plasma, buffy coat, and onethird of the red blood cells were removed. The remaining cells were transferred to $50 \mathrm{~mL}$ sterile tubes and treated with $18 \mathrm{~mL}$ of ice-cold deionized water, allowing the tubes to gently invert for no longer than 45 s. Then, the $2 \mathrm{~mL} 10 \times \mathrm{PBS}$ solution were added to the tubes to restore the isotonicity conditions, and centrifuged at $1000 \times g$ at $4{ }^{\circ} \mathrm{C}$ for $10 \mathrm{~min}$ to remove the supernatant. The pellet was suspended and washed with 20 $\mathrm{mL}$ free, calcium- and magnesium-free HBSS solution and centrifuged at $850 \times g$ at $4{ }^{\circ} \mathrm{C}$ for $5 \mathrm{~min}$. Finally, the isolated PMNL were cultured with RPMI-1640 medium supplemented with $5 \%$ inactivated $\mathrm{FBS}$ and $4 \mathrm{mmol} / \mathrm{L}$ glutamine.

\section{Bacterial strain and culture}

Staphylococcus aureus (ACTT29213) were obtained from American Type Culture Collection. This strain is isolated from the bovine mastitis. The $S$. aureus were cultured in brain heart infusion (LandBridge, Beijing, China) media at $37^{\circ} \mathrm{C}$ and grown for $12-18 \mathrm{~h}$ before use.

\section{Assay of proliferative activity}

The proliferative effects of TTO on BMECs was determined using the Cell Counting Kit-8 (CCK-8; Dojindo, Shanghai, China), according to the manufacturer's protocol. The BMECs $\left(5 \times 10^{3}\right.$ cells/well $)$ were seeded into 96 well plates. After $12 \mathrm{~h}$, BMECs were incubated in DMEM/F12 medium with 0.1\% DMSO and either 0, $0.0125 \%, 0.025 \%, 0.05 \%$, or $0.1 \%$ TTO $(n=4)$ for $6 \mathrm{~h}$. Subsequently, $10 \mu \mathrm{L}$ CCK- 8 reagent was added to cells, followed by incubation at $37^{\circ} \mathrm{C}, 5 \% \mathrm{CO}_{2}$ for $2 \mathrm{~h}$. Absorbance at $450 \mathrm{~nm}$ was then measured in each well using an auto-microplate reader (Thermo Scientific, Shanghai, China).

\section{Cell viability assay}

BMECs were seeded into 96-well plates $\left(5 \times 10^{3}\right.$ cells/ well), and $S$. aureus $\left(5 \times 10^{3} \mathrm{CFU} /\right.$ well $)$ added after $12 \mathrm{~h}$. Cells were then cultured in DMEM/F12 medium in the absence of $S$. aureus and TTO (control group), in the presence of $S$. aureus and absence of TTO (S. aureus group), and in the presence of $S$. aureus and 0, 0.0125\%,
$0.025 \%, 0.05 \%$, or $0.1 \%$ TTO (TTO-treated groups) for $6 \mathrm{~h}(n=4)$. After incubation, cells were vigorously washed five times with $200 \mu \mathrm{L}$ of sterile water and incubated with $200 \mu \mathrm{L}$ DMEM/F12 supplemented with $10 \mu \mathrm{L}$ of CCK- 8 at $37^{\circ} \mathrm{C}$ and $5 \% \mathrm{CO}_{2}$ for $2 \mathrm{~h}$. Absorbance at $450 \mathrm{~nm}$ was then measured in each well using an automicroplate reader. Cell viability $(\%)=($ treatment OD blank OD)/(control OD - blank OD).

\section{S. aureus growth assay}

S. aureus were seeded into 96-well plates $\left(1 \times 10^{5} \mathrm{CFU} /\right.$ well) in BHI medium supplemented with TTO at concentrations of $0,0.0125 \%, 0.025 \%, 0.05 \%$, or $0.1 \%$ TTO $(n=3)$ at $37^{\circ} \mathrm{C}, 5 \% \mathrm{CO}_{2}$ for $3,6,12$, or $24 \mathrm{~h}$, respectively. This was serially diluted and plated on to solid BHI nutrient agar. The number of $S$. aureus was determined by colonies count after $12 \mathrm{~h}$ culture at $37^{\circ} \mathrm{C}$.

\section{S. aureus biofilm formation assay}

Biofilm formation was evaluated as described previously [20]. Briefly, S. aureus were seeded into 96 -well plates $\left(2 \times 10^{6} \mathrm{CFU} /\right.$ well $)$ and incubated at $37^{\circ} \mathrm{C}, 5 \% \mathrm{CO}_{2}$ for $24 \mathrm{~h}$. Supernatants were then removed, BHI medium supplemented with 0 (control group), $0.00625 \%$, $0.0125 \%, 0.025 \%, 0.05 \%$, or $0.1 \%$ TTO $(n=4)$ added, and plates wrapped with Parafilm and incubated at $37^{\circ} \mathrm{C}, 5 \%$ $\mathrm{CO}_{2}$ for $36 \mathrm{~h}$. Next, the plates were rinsed five times with sterile distilled water, and $S$. aureus fixed with $100 \mu \mathrm{L}$ of methyl alcohol for $15 \mathrm{~min}$, and the supernatant removed. The plates were allowed to dry naturally at room temperature, and then treated with $200 \mu \mathrm{L} 0.1 \%$ crystal violet at room temperature for 10 to $15 \mathrm{~min}$. Plates were then rinsed five times, allowed to air dry overnight, and $30 \%$ acetic acid in sterile distilled water $(200 \mu \mathrm{L})$ then added to each well. Plates were incubated with shaking for $1 \mathrm{~h}$, and the solution in each well transferred to a new 96-well plate. To examine $S$. aureus biofilm formation, absorbance at $540 \mathrm{~nm}$ was measured using an auto-microplate reader.

\section{S. aureus association and invasion assay}

To determine the number of $S$. aureus association to BMECs and $S$. aureus invasion of BMECs at different concentrations of TTO, we followed a previously described method [20]. BMECs grown in 24-well plates were infected using DMEM/F12 medium containing $S$. aureus $\left(1 \times 10^{5} \mathrm{CFU} /\right.$ well $)$ at MOI of 1 , and treated with 0 (control group), $0.025 \%, 0.05 \%$, or $0.1 \%$ TTO $(n=3)$ at $37^{\circ} \mathrm{C}, 5 \% \mathrm{CO}_{2}$ for $3 \mathrm{~h}$. Cells were then washed five times with sterile PBS, and treated with $0.1 \%$ Triton X-100, and incubated for $15 \mathrm{~min}$ at $37^{\circ} \mathrm{C}, 5 \% \mathrm{CO}_{2}$. S. aureus association to BMECs were then serially diluted and plated on to solid BHI nutrient agar for colonies count. For the analysis of $S$. aureus invasion of BMECs invasion, 
BMECs were treated with $250 \mu \mathrm{g} / \mathrm{mL}$ of gentamicin at $37^{\circ} \mathrm{C}, 5 \% \mathrm{CO}_{2}$ for $1 \mathrm{~h}$, then washed five times with $\mathrm{PBS}$ to remove the gentamicin. Cells were lysed with $0.5 \%$ Triton X-100 for $15 \mathrm{~min}$. The remaining live bacteria were then serially diluted, seeded in solid BHI agar plates, and CFUs counted.

\section{Scanning electron microscope}

S. aureus $\left(4 \times 10^{5} \mathrm{CFU} /\right.$ well $)$ were seeded into the 8-well glass chamber slides in BHI medium, and incubated for $6 \mathrm{~h}$ at $37^{\circ} \mathrm{C}, 5 \% \mathrm{CO}_{2}$. Then, $S$. aureus were washed three times with $200 \mu \mathrm{L}$ of sterile PBS, and incubated with $0.05 \%$ TTO for 6 h at $37^{\circ} \mathrm{C}, 5 \% \mathrm{CO}_{2}$. S. aureus without TTO treatment were used as a control. Next, S. aureus were washed three times with $200 \mu \mathrm{L}$ of sterile PBS and fixed with $200 \mu \mathrm{L} 2.5 \%$ glutaraldehyde at $4{ }^{\circ} \mathrm{C}$ for overnight. Then, S. aureus were washed three times with $200 \mu \mathrm{L}$ of sterile PBS, and successively dehydrated with $30 \%, 50 \%, 70 \%, 80 \%, 90 \%, 95 \%, 100 \%$ ethyl alcohol, and $100 \%$ ethyl alcohol with $\mathrm{Na}_{2} \mathrm{SO}_{4}$ for 15 min. These slides were dried by automatic critical point dryer (EM CPD300, Leica, Germany), and these slides surface were gold-plated by high vacuum turbo evaporator (EM SCD500, Leica, Germany). The S. aureus samples were observed for SEM (Gemini SEM 300, Carl Zeiss, Germany).

\section{PMNL chemotaxis assay}

The BMECs were seeded into 6-well plates $\left(2.5 \times 10^{5}\right.$ cells/well). After $12 \mathrm{~h}$, the supernatant was removed, and cells washed three times with PBS. BMECs were then incubated in in RPMI-1640 medium (as control group), in the presence of $0.05 \%$ TTO and absence of $S$. aureus (TTO-treated group), in the presence of $S$. aureus and absence of TTO (S. aureus-treated group), or in the presence of $S$. aureus and $0.05 \%$ TTO (TTO and $S$. aureus treated groups) for $6 \mathrm{~h}(n=3)$. Then, Supernatants were then filtered through $0.22 \mu \mathrm{m}$ sterile filters to collect media containing high levels of the chemoattractant, IL-8. Next, $500 \mu \mathrm{L}$ of medium containing IL-8 was added to the bottom wells of 24-well plates. The chambers (pore size, $5.0 \mu \mathrm{m}$; diameter, $6.5 \mathrm{~mm}$; Corning) were placed in the top of wells, and $100 \mu \mathrm{L}$ PMNL suspension $\left(5 \times 10^{5}\right.$ cells/chamber $)$ were seeded into the chambers. All samples were incubated at $37^{\circ} \mathrm{C}, 5 \% \mathrm{CO}_{2}$ for $2 \mathrm{~h}$. Subsequently, chambers were rinsed vigorously three times with $100 \mu \mathrm{L}$ of CMF-HBSS, and the number of PMNL that had migrated to the bottom wells were determined. For effect of TTO on PMNL chemotaxis, PMNL were seeded into 12-well plates $\left(6 \times 10^{6}\right.$ cells/ well), and pretreated with RPMI-1640 medium containing $0.05 \%$ TTO $(n=5)$ for $2 \mathrm{~h}$ at $37^{\circ} \mathrm{C}, 5 \% \mathrm{CO}_{2}$. Next, $600 \mu \mathrm{L}$ of medium containing a final concentration of $100 \mathrm{ng} / \mathrm{mL}$ IL-8 (Peprotech) were added to the bottom wells of 24-well plates. The chambers (pore size, $5.0 \mu \mathrm{m}$; diameter, $6.5 \mathrm{~mm}$ ) were placed in the top of wells, and $100 \mu \mathrm{L}$ PMNL suspension $\left(6 \times 10^{5}\right.$ cells/chamber $)$ were seeded into the chambers. All samples were incubated at $37^{\circ} \mathrm{C}, 5 \% \mathrm{CO}_{2}$ for $2 \mathrm{~h}$. Subsequently, chambers were rinsed vigorously three times with $100 \mu \mathrm{L}$ of CMF-HBSS, and the number of PMNL that had migrated to the bottom wells were determined.

\section{Quantitative RT-PCR}

For the expression of genes involved in the inflammatory response of BMECs exposed with $S$. aureus, BMECs $\left(2 \times 10^{5}\right.$ cells/well $)$ were seeded in 6 -well plates and grown at $37^{\circ} \mathrm{C}, 5 \% \mathrm{CO}_{2}$. Cells were divided into four experimental groups as follows: 1) Control, DMEM/F12 medium; 2) TTO treatment, DMEM/F12 medium containing 0.05\% TTO; 3) S. aureus treatment, DMEM/F12 medium supplemented with $S$. aureus. 4) $S$. aureus and 0.05\% TTO treatment, DMEM/F12 medium supplemented with both $S$. aureus and $0.05 \%$ TTO treatment. All treatments were incubated for $6 \mathrm{~h}$.

Six mid-lactating Holstein cows were selected to isolate the PMNL for the expression of genes involved in the inflammatory response of PMNL exposed with TTO. PMNL $\left(1.3 \times 10^{6}\right.$ cells/well $)$ were seeded in 24 -well plates, and treated with $0 \%$ TTO or $0.05 \%$ TTO for $2 \mathrm{~h}(n=6)$.

After incubation, total RNA was isolated from the cultured cells using a TRIzol kit (Tiangen, Beijing, China). Reverse transcription (RT) was performed using an RT Kit (Takara, Beijing, China). RT reaction mixtures contained $1 \mu \mathrm{g}$ total RNA and $1 \times$ PrimeScript RT Master Mix in a final volume of $20 \mu \mathrm{L}$, and reactions were performed for $15 \mathrm{~min}$ at $37^{\circ} \mathrm{C}$. Reverse transcriptase was inactivated by heating to $85^{\circ} \mathrm{C}$ for $5 \mathrm{~s}$. qRT-PCR assays were performed using $\mathrm{SYBR}^{\circ}$ Premix Ex $\mathrm{Taq}^{\text {Tw }}$ II Kit (Takara). The qRT-PCR reaction mixture contained $1 \times$ SYBR $^{\circ}$ Premix Ex Taq $^{\text {tm }}$ II, $0.4 \mu \mathrm{mol} / \mathrm{L}$ each forward and reverse primers, and $100 \mathrm{ng} \mathrm{cDNA}$ templates in a final volume of $20 \mu \mathrm{L}$, and reactions were performed as follows: initial denaturation at $95^{\circ} \mathrm{C}$ for $30 \mathrm{~s}$, followed by 40 cycles at $95^{\circ} \mathrm{C}$ for $5 \mathrm{~s}$ and $60^{\circ} \mathrm{C}$ for $30 \mathrm{~s}$. Before the qRT-PCR for samples, the amplification efficiencies of all primers were determined by using standard dilution series. The primers listed in Table 1 are from the previous studies $[19,20]$. Efficiency of these primers were determined in the two study. The relative expression of target genes was normalized by the geometric mean of the 2 selected reference genes GAPDH and $\beta$ actin and calculated using the $2^{-\triangle \Delta C T}$ method.

\section{Statistical analysis}

Before data analysis, the distribution of normality and homogeneity of variances were studied with a Kolmogorov-Smirnov and Levene test, respectively. If 
Table 1 Primers for real-time PCR analyses ${ }^{a}$

\begin{tabular}{|c|c|c|c|}
\hline Gene & Primer sequence ( $5^{\prime}$ to $3^{\prime}$ ) & Accession number & Size, bp \\
\hline \multirow[t]{2}{*}{ GAPDH } & F:GGGTCATCATCTCTGCACCT & NM_001034034 & 176 \\
\hline & R:GGTCATAAGTCCCTCCACGA & & \\
\hline \multirow[t]{2}{*}{ IL-6 } & F:TCCTTGCTGCTITCACACTC & NM_173923.2 & 129 \\
\hline & R:CACCCCAGGCAGACTACTTC & & \\
\hline \multirow[t]{2}{*}{$I L-1 \beta$} & F:CAGTGCCTACGCACATGTCT & NM_174093.1 & 209 \\
\hline & R:AGAGGAGGTGGAGAGCCTTC & & \\
\hline \multirow[t]{2}{*}{ TNF- $a$} & F:GCCCTCTGGTTCAGACACTC & NM_173966.3 & 192 \\
\hline & R:AGATGAGGTAAAGCCCGTCA & & \\
\hline \multirow[t]{2}{*}{ TLR-2 } & F:CAGGCTTCTTCTCTGTCTTGT & NM_174197.2 & 140 \\
\hline & R:CTGTTGCCGACATAGGTGATA & & \\
\hline \multirow[t]{2}{*}{ IL-8 } & F:TGGGCCACACTGTGAAAAT & NM_173925.2 & 136 \\
\hline & R:TCATGGATCTTGCTTCTCAGC & & \\
\hline \multirow[t]{2}{*}{ k-casein } & F: CCAGGAGCAAAACCAAGAAC & NM_174294.2 & 148 \\
\hline & R: TGCAACTGGTITCTGTTGGT & & \\
\hline \multirow[t]{2}{*}{ IL-10 } & F:TGTATCCACTTGCCAACCAG & NM_174088.1 & 126 \\
\hline & R:CAGCAGAGACTGGGTCAACA & & \\
\hline \multirow[t]{2}{*}{ L-selectin } & F:CTCTGCTACACAGCTTCTTGTAAACC & NM_174182.1 & 104 \\
\hline & R:CCGTAGTACCCCAAATCACAGTT & & \\
\hline \multirow[t]{2}{*}{ IRAKI } & F: CCTCAGCGACTGGACATCCT & NM_001040555.1 & 103 \\
\hline & R:GGACGTTGGAACTCTTGACATCT & & \\
\hline \multirow[t]{2}{*}{ NFKBIA } & F:GGGAGACCTGGCCTTCCTC & NM 001045868.1 & 101 \\
\hline & R:CCAGAAGTGCCTCAGCGATT & & \\
\hline \multirow[t]{2}{*}{ TRAF6 } & F:AGAACAGATGCCCAATCACTATGAT & NM_001034661.2 & 100 \\
\hline & R:GTGATTCCTCTGCATCTIITCATG & & \\
\hline \multirow[t]{2}{*}{ Lysozyme } & F:GAGAGATGTGAGCTTGCCAGAA & NM_001078159.1 & 120 \\
\hline & R:TGTAGCTTGTGTGTTGTAATTGCTTTC & & \\
\hline \multirow[t]{2}{*}{ SOD2 } & F:GAGAAGGGTGATGTTACAGCTCAGA & NM_201527.2 & 100 \\
\hline & R:GGCTCAGATTTGTCCAGAAGATG & & \\
\hline \multirow[t]{2}{*}{ TLR-4 } & F:GACCCTTGCGTACAGGTTGT & NM_174198.6 & 103 \\
\hline & R:GGTCCAGCATCTTGGTTGAT & & \\
\hline \multirow[t]{2}{*}{$\beta$-actin } & F:GACCCAGATCATGTTCGAGA & NM_173979.3 & 145 \\
\hline & R:CTCATAGATGGGCACCGTGT & & \\
\hline
\end{tabular}

${ }^{a}$ Abbreviations: GAPDH Glyceraldehyde-3-phosphate dehydrogenase, IRAK1 Interleukin 1 receptor associated kinase 1, NFKBIA NFKB inhibitor alpha, TRAF6 TNF receptor associated factor $6, S O D 2$ superoxide dismutase 2, TLR-2 Toll like receptor 2, TLR-4 Toll like receptor 4, F Forward; $R$ Reverse

the data were the distribution of normality and homogeneity of variances were equal, statistical analysis was evaluated by One-way analysis of variance (ANOVA), followed by determination of the least significant difference (LSD) for post-hoc multiple comparisons of treatment means and tested by the independent sample $\mathrm{t}$ test, using SPSS 19.0 software (SPSS Inc.; Chicago, IL, USA). Otherwise, a Kruskal-Wallis was performed using the non-parametric test for statistical analysis. The gene expression for the $2^{-\Delta \Delta \mathrm{Ct}}$ and cell viability assays were $\log _{10}$ transformed for statistical analysis. $P$ values of $<0.05$ were considered significant.

\section{Results}

TTO extracts phytochemical composition

The phytochemical composition of tea tree essential oil preliminary product treated by pressure and temperature change in reaction still showed the presence of terpinen4-ol, $\alpha$-terpinene, $\alpha$-terpineol, $\alpha$-pinene, $\mathrm{p}$-cymene, and 1,8-cineole, $\gamma$-Terpinene, terpinolene, and pinocarveol (Fig. 1). According to the New Zealand Standard, concentration of terpinen-4-ol constitutes $30-48 \%$ of total effective components in tea tree essential oils preliminary product. Notably, the content of terpinen-4-ol was increased to $60.23 \%$ after the preliminary product were 


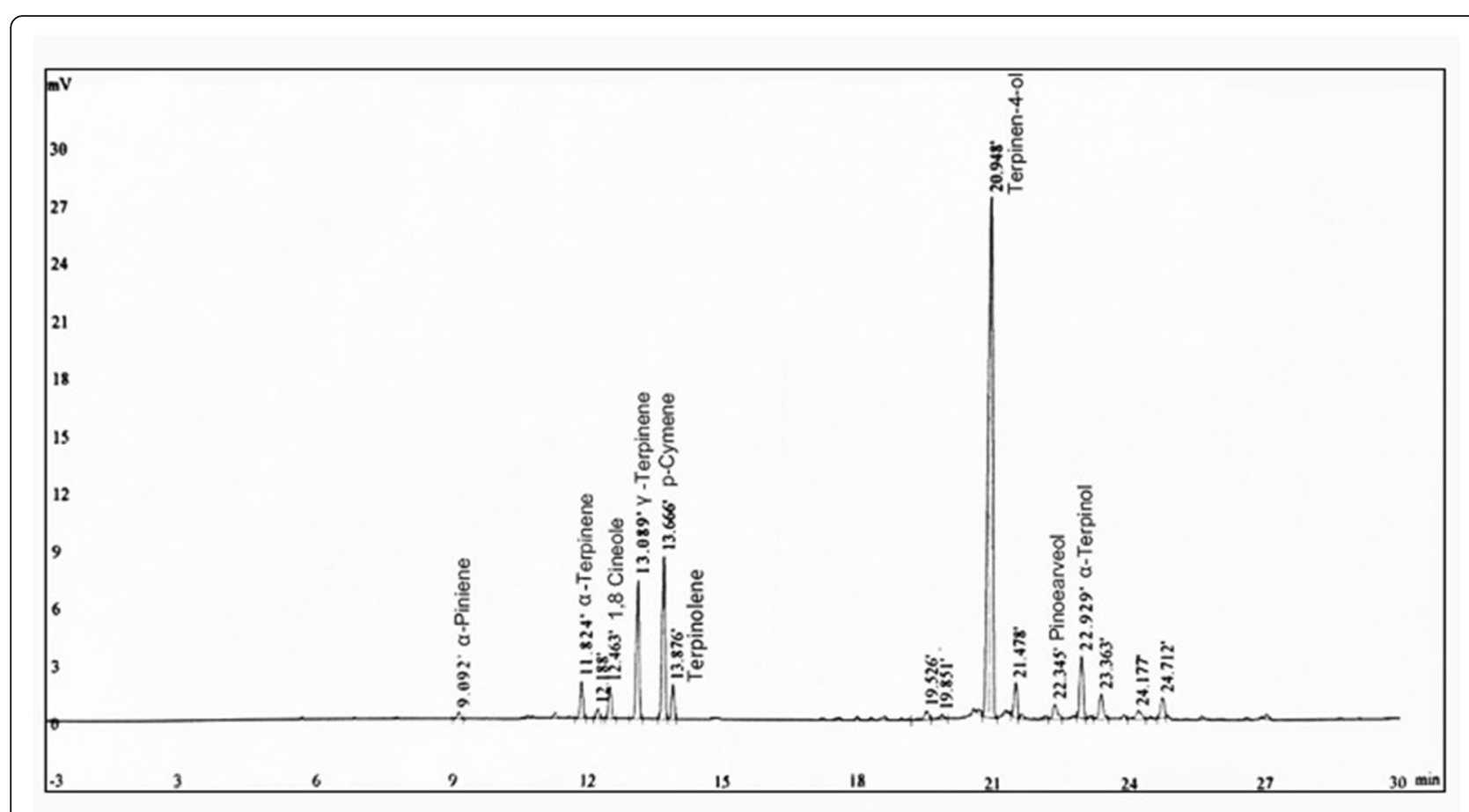

Fig. 1 The analysis of TTO extracts major component. Representative chromatogram with the identified major component peaks

treated by pressure and temperature change in reaction still. In addition, TTO extracts have less $0.05 \% \mathrm{p}$ cymene which is hazardous for human and animals, compared with p-cymene (1.7\%) in New Zealand Standard. In addition, $\alpha$-pinene, $\alpha$-Terpinene, $\gamma$-Terpinene decreased approximately 4,8 , and 3 folds, relatively to $\alpha$ pinene (2.1\%), $\alpha$-Terpinene (3\%), $\gamma$-Terpinene $(17.8 \%)$ in New Zealand Standard.
Assessment of the proliferative effects of TTO on BMECs

The relationship between concentration of TTO and their proliferative effect on BMECs was examined by CCK-8 assay. As shown in Fig. 2, results of the proliferative assays demonstrated that concentrations of $0.025 \%$ $(P=0.02)$ and $0.05 \%(P=0.02)$ TTO were able to increase proliferation of BMECs, compared with the untreated control group (Fig. 2a). In contrast, $0.1 \%$ TTO
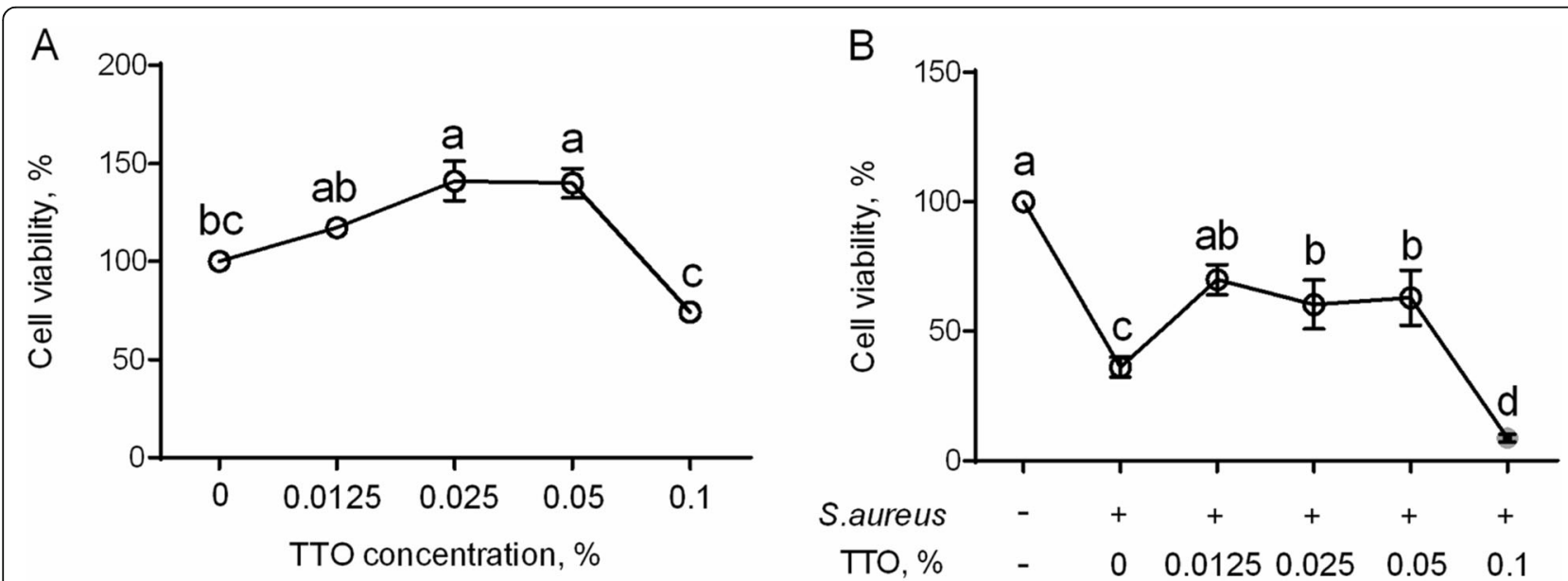

Fig. 2 The protective effects of TTO on bovine mammary epithelial cells (BMECs). (a) Evaluation of proliferative effects of TTO on BMECs. The BMECs were incubated with 0 (control group), $0.0125 \%, 0.025 \%, 0.05 \%$, or $0.1 \%$ TTO for $6 \mathrm{~h}$. (b) Viability of BMECs exposed to S. aureus with or without TTO treatment. BMECs were cultured in the absence of $S$. aureus and TTO (control group), in the presence of $S$. aureus and absence of TTO (S. aureus group), and in the presence of S. aureus and $0.0125 \%, 0.025 \%, 0.05 \%$, or $0.1 \%$ TTO (TTO-treated groups) for $6 \mathrm{~h}$. Data are presented as the means $\pm \operatorname{SEM}(n=4)$. Means at the different concentration of TTO with different letters $(\mathbf{a}$-d $)$ differ significantly for treatment effect 
significantly inhibited BMECs viability, relatively to $0.025 \%$ and $0.05 \%$ concentrations (Fig. $2 \mathrm{a}$ ). In comparison with controls, BMECs exposed to $S$. aureus exhibited $(P<0.001)$ reduced viability, whereas $0.0125 \%(P=$ $0.002), 0.025 \%(P=0.015)$, and $0.05 \%(P=0.01)$ TTO enhanced the viability of BMECs exposed to $S$. aureus, relatively to $S$. aureus treatment alone (Fig. 2b). However, viability of BMECs exposed with $S$. aureus was inhibited at concentration of $0.1 \%$ TTO (Fig. 2b). The current results demonstrate that addition of $0.0125 \%$, $0.025 \%$, and $0.05 \%$ TTO in vitro can promote the viability of BMECs exposed to S. aureus.

\section{Antibacterial activity}

The growth of $S$. aureus was reduced at most of TTO concentrations and time points (Fig. 3a). S. aureus treated with TTO extracts showed a slow growth by incubation from 3 and $6 \mathrm{~h}$ (Fig. 3a). In addition, we also evaluated the effect of TTO on S. aureus biofilm formation in present study. Our data showed that at the concentrations of $0.025 \%, 0.05 \%$, and $0.1 \%$ TTO failed to form a $S$. aureus biofilm compared with controls (Fig. 3b). Subsequently, we also investigated the effect of TTO on S. aureus association to BMECs and S. aureus invasion of BMECs. The present study showed that association of $S$. aureus to BMECs and invasion of $S$. aureus into BMECs were significantly reduced by treatment with $0.05 \%$ and $0.1 \%$ TTO, compared with control group (Fig. 3c and d). To validate whether addition of TTO have a profound change in the morphological state and structure of $S$. aureus, we observe the morphological state of $S$. aureus by scanning electron microscope (SEM). The S. aureus maintains the intact morphology state and structure in the cell surface in the absence of TTO treatment, whereas TTO treatment showed a profound alter in the cell surface, and the $S$. aureus surface become sunk (Fig. 4). These results demonstrated that TTO can reduce the $S$. aureus growth and biofilm formation, and it also prevents invasion of $S$. aureus into BMECs, helping the antimicrobial agents to cure the persistent and chronic infections.

\section{Effect of TTO on the innate immune response of PMNL}

The mRNA levels of genes encoding the cytokines, signaling factors, recognition receptor, and pathogen response elements were determined by qRT-PCR (Table 2). Compared with the untreated control group, PMNL treated with $0.05 \%$ TTO did not have profound alters $(P>0.05)$ in expression of IL-1 $\beta$, IL-6, and IL-8. In addition, chemotactic ability of PMNL by IL-8 induction was not changed $(P=0.098)$ after pre-treatment of PMNL with $0.05 \%$ TTO (Fig. 5). Notably, IL-10 ( $P=$ $0.001)$ and TNF- $\alpha(P=0.02)$ were significantly attenuated in PMNL incubated with $0.05 \%$ TTO. For adhesion molecule and pattern recognition receptor, expression of TLR-2, TLR-4 and L-selectin were not changed $(P>$ $0.05)$ by TTO treatment. For these genes involved in NF- $\kappa B$ signal pathway, expression of interleukin 1 receptor associated kinase 1 (IRAKI) was not changed after pre-treatment of PMNL with TTO. Remarkably, NFKB inhibitor alpha (NFKBIA) was significantly attenuated $(P=0.02)$ in PMNL incubated with TTO. For genes related to the killing of pathogens, expression of lysozyme was not affected by the incubation of PMNL with TTO.

\section{Effect of TTO on the innate immune response of BMECs exposed with $S$. aureus}

The quantitative PCR performance results related to the inflammatory response of BMECs are shown in Table 3. The proinflammatory cytokines IL-1 $\beta$, IL-6, and TNF- $\alpha$ were significantly downregulated $(P<0.001)$ by the incubation of TTO. Interestingly, addition of TTO enhanced $(P<0.001)$ the expression of IL- 8 in BMECs, relatively to untreated control. Remarkably, TTO enhanced the PMNL ability to migrate in $S$. aureus-exposed BMECs, compared with $S$. aureus alone (Fig. 6). In comparison with control, TLR-2 was attenuated by the incubation of TTO $(P=0.02)$, but TLR-4 was not affected. Importantly, TTO did not change the expression of $\mathrm{k}$-casein in BMECs challenged with $S$. aureus when compared with S. aureus treatment alone.

\section{Discussion}

The bovine mammary epithelium is the first line of defense against invasion of pathogen bacteria, and is vital role in the innate immune response to alleviate the severity of infections [21]. The mammary epithelium infected with pathogen elicits the release of inflammatory mediators, mounting the innate immune responses to enhance the resolution of pathogenic bacterial infection [22]. However, the inflammatory response of mammary epithelium caused by $S$. aureus infection is usually slow, and the infection frequently becomes persistent [23]. The adhesion of $S$. aureus to mammary epithelial cells is as initial step in pathogenesis [24]. The adhesion is associated with the non-specific or specific binding between bacterial cell-associated ligands and host cell surface receptors, and there is strong evidence that invasion of mammary epithelial cells by bacterium is related to an endocytic process, allowing the interaction between bacteria and host cells via surface proteins [24]. Persistent and chronic infections caused by $S$. aureus is a serious problem due to $S$. aureus invasion into BMECs, and only extracellular bacteria is treated by antimicrobial agents, but $S$. aureus within cells is protected from antimicrobials [25]. In addition, the biofilm matrix is a complex mixture of macromolecules containing exopolysaccharides, proteins and DNA that bind to the bacterial surface 


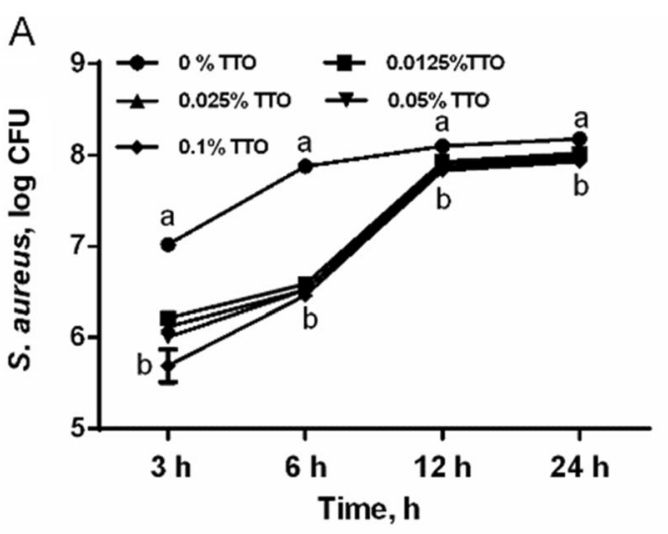

C

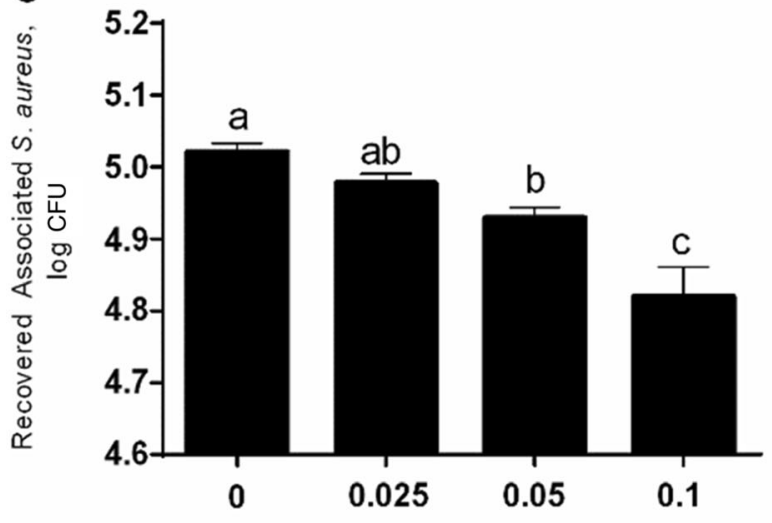

TTO concentration, \%

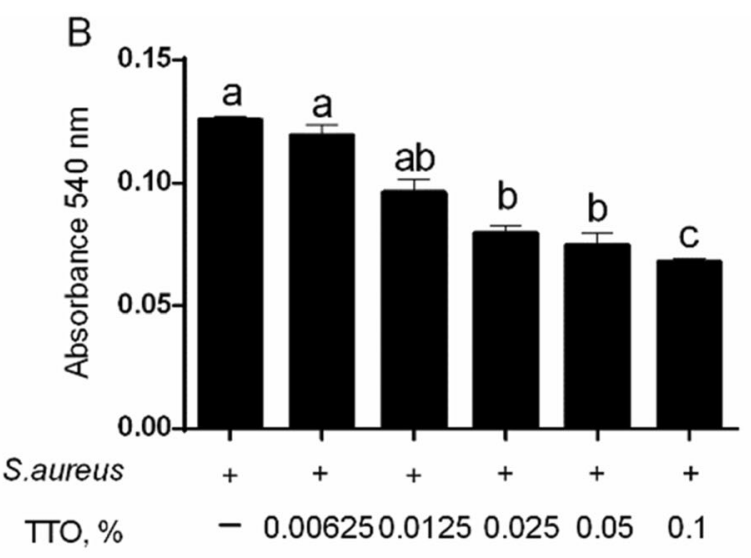

D

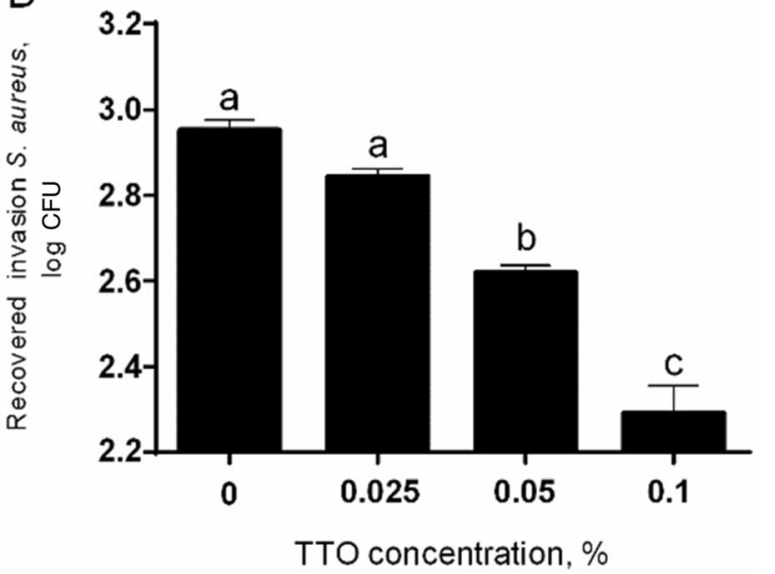

Fig. 3 Evaluation of antibacterial effect of TTO. (a) The growth inhibition of S. aureus during $24 \mathrm{~h}$ treatment with $0,0.0125 \%, 0.025 \%, 0.05 \%$, or $0.1 \%$ TTO $(n=3)$. Log CFU bacteria were measured after $3 \mathrm{~h}, 6 \mathrm{~h}, 12 \mathrm{~h}$, and $24 \mathrm{~h}$. Means at the same time point with different letters $(\mathbf{a}$, $\mathbf{b})$ differ significantly for treatment effect. (b) Biofilm formation. The S. aureus cultures were incubated with 0 (control group), 0.00625\%, 0.0125\%, 0.025\%, $0.05 \%$, or $0.1 \%$ TTO $(n=6)$ and absorbance at $540 \mathrm{~nm}$ measured. (c) The association of BMECs. The BMEC were incubated in DMEM/F12 medium containing S. aureus and 0 (control group), $0.025 \%, 0.05 \%$, or $0.1 \%$ TTO $(n=3)$. (d) The invasion of BMECs. The BMEC were incubated in DMEM/ F12 medium containing S. aureus and 0 (control group), $0.025 \%, 0.05 \%$, or $0.1 \% \Pi \mathrm{TO}(n=3)$. Data are presented as the means \pm SEM. Means at the different concentration of TTO with different letters $(a-c)$ differ significantly for treatment effect
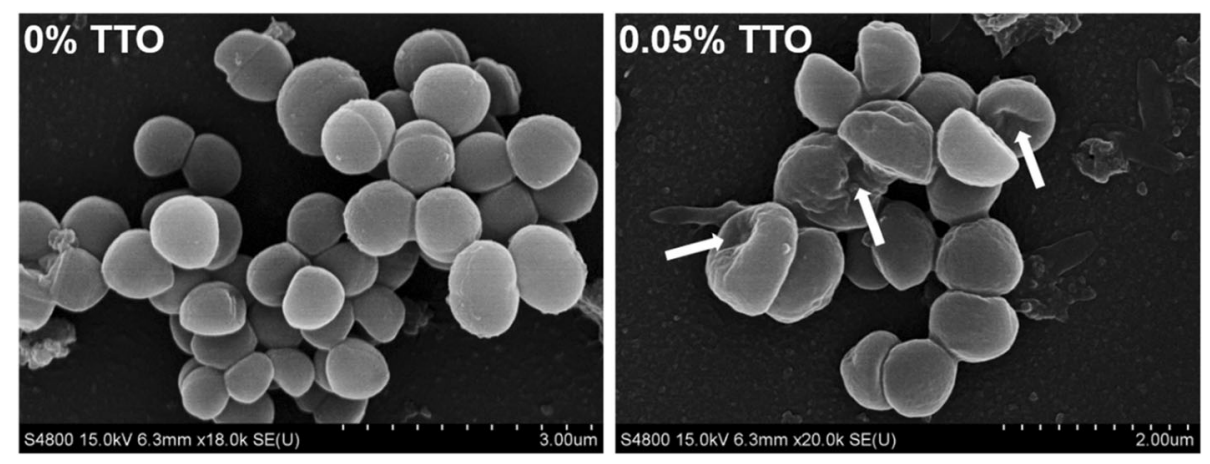

Fig. 4 Scanning electron microscopy to evaluate the morphological state of S. aureus with TTO. S. aureus were incubated with 0 (control) or $0.05 \%$ tee trea oil (TTO) for $6 \mathrm{~h}$ in vitro. White arrowheads indicate S. aureus showing a sunken morphology state 
Table 2 Expression of genes in PMNL incubated with 0 (control) or $0.05 \%$ tee trea oil (TTO) in vitro

\begin{tabular}{lllll}
\hline Symbol & \multicolumn{1}{l}{ Treatment $^{1}$} & & SEM & P-value \\
\cline { 2 - 4 } & Control & TTO & & \\
\hline IL-1 $\beta$ & 1.43 & 0.86 & 0.23 & 0.38 \\
IL-6 & 1.19 & 1.38 & 0.22 & 0.81 \\
IL-8 & 1.21 & 1.25 & 0.18 & 0.93 \\
IL-10 & $1.24^{\mathrm{a}}$ & $0.16^{\mathrm{b}}$ & 0.18 & 0.001 \\
TNF-a & $1.14^{\mathrm{a}}$ & $0.42^{\mathrm{b}}$ & 0.46 & 0.02 \\
TLR-2 & 1.49 & 0.41 & 0.47 & 0.05 \\
TLR-4 & 1.25 & 0.94 & 0.13 & 0.49 \\
L-seletin & 1.07 & 1.13 & 0.11 & 0.88 \\
IRAKI & 1.05 & 0.83 & 0.12 & 0.24 \\
NFKBIA & $1.05^{\mathrm{a}}$ & $0.52^{\mathrm{b}}$ & 0.13 & 0.02 \\
TRAF-6 & 1.04 & 0.93 & 0.09 & 0.51 \\
Lysozyme & 1.30 & 0.74 & 0.21 & 0.23 \\
SOD2 & 1.16 & 0.67 & 0.20 & 0.14 \\
\hline
\end{tabular}

$\mathrm{a}, \mathrm{b}$ Means in the same row with different superscripts differ significantly for treatment effect

'PMNL from six mid-lactating Holstein cows were incubated in DMEM/F12 medium in the absence of $\pi \mathrm{T}$ (control group) or in the presence of $0.05 \%$ TाO $(n=6)$

[26]. The surface biofilms are resistant to antibiotics treatment and as effective barrier against the immune cells response, and actively response to some persistent and chronic infection $[27,28]$. In present study, the phytochemical composition of TTO extract exhibit the presence of terpinen-4-ol, $\alpha$-terpinene, $\alpha$-terpineol, $\alpha$ pinene, p-cymene, and 1,8-cineole, $\gamma$-terpinene, terpinolene, and pinocarveol. Remarkably, the concentration of terpinen-4-ol involved in the antibacterial activity [12] contains approximately $60.23 \%$. The phytochemical composition of $\mathrm{p}$-cymene involved in the hazards for human and animals show less $0.05 \%$ concentration. These

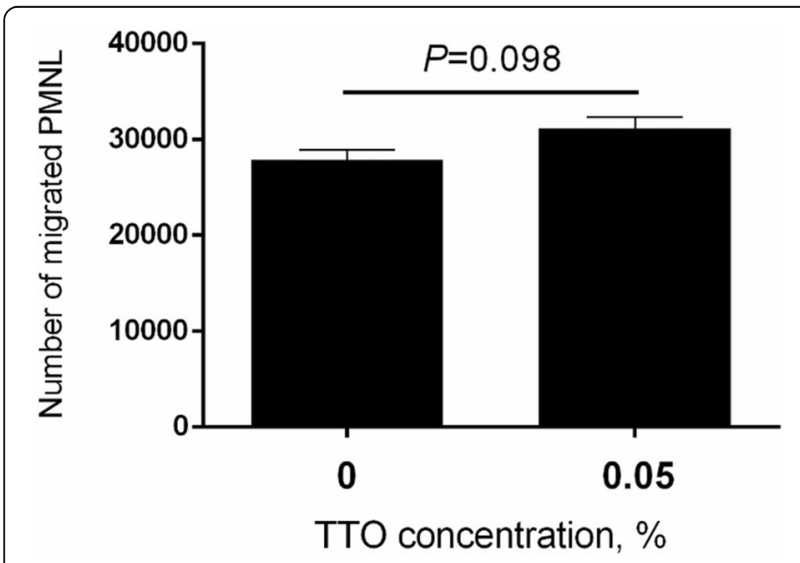

Fig. 5 Number of migrated PMNL in response to IL-8 chemokine after PMNL were pretreated with either 0 (control) or $0.05 \%$ TTO for $2 \mathrm{~h}$ in vitro. Data are presented as the means $\pm \operatorname{SEM}(n=5)$ results indicate that TTO extracts exhibited a positive role for the antibacterial properties and safer for human and animals. To our knowledge, no study has investigated the effect of TTO on S. aureus biofilm formation, $S$. aureus association to BMECs and invasion of $S$. aureus into BMECs. Therefore, the development of alternative, nontoxic agents for the resolution bovine mastitis triggered by $S$. aureus are urgent need for improving milk quality and human health.

TTO has beneficial role in antibacterial activity and anti-inflammatory properties [12]. Our results demonstrated that $0.025 \%$ and $0.05 \%$ TTO were able to increase proliferation of BMECs. Previous study reported that $10 \%$ TTO is able to inhibit the proliferation of melanoma cells and overcoming the resistance to multidrug [29]. Our results indicate that low concentration of TTO did not impair the BMECs function, and may promote the innate immune response of BMECs to be effective role for the resolution of bovine mastitis. Notably, $0.0125 \%, 0.025 \%$, and $0.05 \%$ TTO significantly enhanced the viability of BMECs exposed to S. aureus, compared with $S$. aureus treatment alone, suggesting that TTO may be able to mount the innate immune responses to reduce the $S$. aureus damage to BMECs. In this process, TTO exerts a positive role by reducing the effects of $S$. aureus on the BMECs, but not by moderating effects of BMECs. For antibacterial activity, addition of TTO decreases the $S$. aureus growth and biofilm formation, indicating that TTO have a positive role in preventing and controlling biofilm formation strategy in the context of bovine mastitis caused by $S$. aureus. The association of $S$. aureus to BMECs and invasion of $S$. aureus into BMECs were significantly reduced by treatment with $0.05 \%$ and $0.1 \%$ TTO, suggesting that TTO can promote and help the antimicrobial agents to cure the persistent and chronic infections caused by S. aureus. During the bovine mastitis, the bacteria often attacks the mammary epithelial cells and impairs cells function that fail to solve the immune response against the bacterial infection [24], whereas TTO is probably effective role in mediating the protective immune response of BMECs.

During bovine mastitis, circulating blood PMNL were actively recruited to mammary gland infected by pathogen for alleviating the inflammatory response and elimination of pathogen $[18,30]$, and eventually these PMNL migrated to mammary gland become the predominant somatic cells in milk [31]. Therefore, PMNL play a decisive role for resolution of mastitis. The recruitment process of PMNL is controlled by chemoattractants, such as IL-8, C-C motif ligand, and C-X-C motif ligand chemokines released by resident immune cells and mammary epithelial cells [20]. In the current study, chemotactic ability of PMNL by IL-8 induction was not altered after pre-treatment of PMNL with $0.05 \%$ of 
Table 3 Expression of genes in BMECs incubated with 0 (control) or 0.05\% tea tree oil (TTO) or S. aureus or S. aureus with $0.05 \%$ TTO in vitro

\begin{tabular}{|c|c|c|c|c|c|c|c|c|}
\hline \multirow[t]{2}{*}{ Symbol } & \multicolumn{4}{|c|}{ Treatment $^{1}$} & \multirow[b]{2}{*}{ SEM } & \multicolumn{3}{|l|}{$P$-value } \\
\hline & Control & TTO & S.aureus & S. aureus with TTO & & A & $\mathrm{B}$ & $\mathrm{A} \times \mathrm{B}$ \\
\hline TLR-2 & 1.00 & 0.46 & 1.80 & 0.52 & 0.25 & 0.02 & 0.22 & 0.28 \\
\hline$T L R-4$ & 1.00 & 0.83 & 0.61 & 0.64 & 0.26 & 0.63 & 0.06 & 0.49 \\
\hline$I L-1 \beta$ & 1.00 & 0.39 & 1.25 & 0.59 & 0.37 & $<0.001$ & 0.02 & 0.75 \\
\hline IL-6 & 1.00 & 0.22 & 1.18 & 0.59 & 0.41 & $<0.001$ & 0.008 & 0.25 \\
\hline TNF-a & 1.01 & 0.08 & 0.97 & 0.14 & 0.47 & $<0.001$ & 0.91 & 0.51 \\
\hline $\operatorname{IL}-8$ & 1.00 & 3.69 & 1.97 & 3.57 & 1.26 & $<0.001$ & 0.20 & 0.12 \\
\hline$k$-casein & 1.00 & 1.48 & 1.24 & 1.06 & 0.25 & 0.22 & 0.42 & 0.02 \\
\hline
\end{tabular}

${ }^{1}$ BMECs were cultured in DMEM/F12 medium in the absence of $S$. aureus and TTO (control group), or in the absence of $S$. aureus and presence of $0.05 \%$ TTO, or in the presence of $S$. aureus and absence of $T T O$, or in the presence of $S$. aureus and $0.05 \% \pi O(n=3)$. A, TTO treatment; B, S. aureus treatment

TTO. During the bacterial infection, PMNL can trigger the profound changes in the adhesion molecules for the resolution of pathogenic bacteria. Toll-like adhesion molecule and pattern recognition receptors can activate the NF- $\mathrm{kB}$ proinflammatory signal pathways that respond to the activation of IRAKI and TRAF-6, and further induce the IKK complex to trigger the phosphorylation of I $\mathrm{B} B$ and the release of NF- $\kappa B$. Subsequently, NF- $\kappa B$ binds to the TNF- $\alpha$, IL- 6 , and IL- $1 \beta$ promoter, leading to their elevation in transcriptional level [32]. To date, no studies have investigated the effect of TTO on the innate immune responses of PMNL. The TLR-2 and TLR-4 recognize the gram-positive and gram-negative bacteria, respectively [33]. Our results show that mRNA

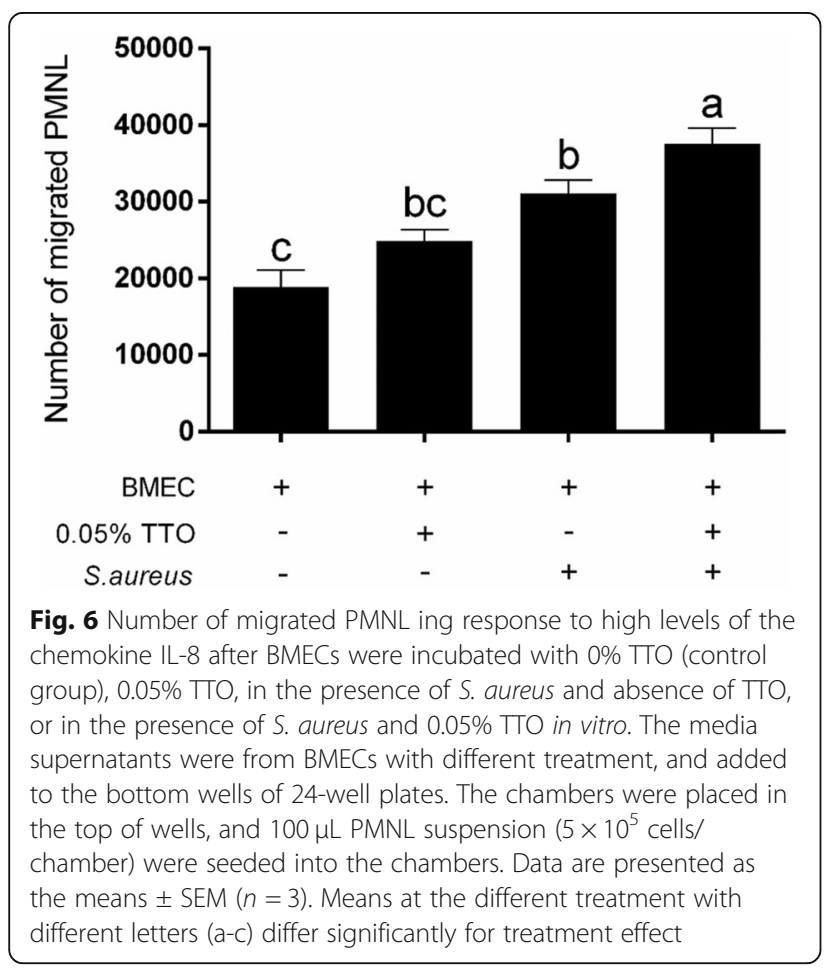

level of TLR-4 was not changed after pre-treatment of PMNL with TTO, but TLR-2 was significantly attenuated in PMNL treated with TTO. Previous study has demonstrated that plant essential oils extract did not have a positive effect against the Gram-negative bacteria [34]. Therefore, TTO modifies the innate immune responses of PMNL by an attenuation in the TLR-2 rather than to TLR-4. In addition, PMNL treated with $0.05 \%$ TTO have no profound changes in the expression of TRAF- 6 and IRAKI. The NFKBIA encoding the IкB $\alpha$ gene was decreased in PMNL with 0.05\% TTO. This downregulation of NFKBIA is probably involved in an attenuation in the NF- $\kappa B$ expression because NF- $\kappa B$ is widely accepted to bind the genes promoter to induce its transcription, and ultimately leading to the overall decrease in the mRNA level of proinflammatory genes. Consistently, our results also show the evidence that TNF- $\alpha$ was attenuated after PMNL treated with TTO, indicating that TTO has a positive role for relieving the inflammatory response.

The BMECs trigger the activation of innate immune responses, and form the first line of defense against invasion of pathogen [21]. During the chronic infections triggered by $S$. aureus, mammary gland actively exerts the protective immune response by chemokines and adhesion molecule induced by mammary epithelial cells. The expression of TLR-2 gene involved in the innate immune response was downregulated by TTO treatment in BMECs challenged with $S$. aureus compared with $S$. aureus alone, however, TLR- 4 was not affected. Remarkably, IL-1 $\beta$, IL- 6 , and TNF- $\alpha$ were attenuated by incubation with $0.05 \%$ TTO in S. aureus-exposed BMECs, relatively to $S$. aureus alone, suggesting that TTO can alleviate the proinflammatory responses effect on $S$. aureus-exposed BMECs. Interestingly, $S$. aureus-exposed BMECs with TTO treatment increased the IL-8 expression. Consistently, $0.05 \%$ TTO enhanced the PMNL ability to migrate in $S$. aureus-exposed BMECs compared with $S$. aureus alone and control because increased the synthesis of IL- 
8 known for PMNL chemotactic function. This finding suggests that blood PMNL migration to mammary cells was elevated to promote the elimination of $S$. aureus and resolution of bovine mastitis when treatment with TTO induces the expression of IL-8 in bovine mammary gland infected by $S$. aureus. To evaluate the safety of TTO extracts for application in bovine in vivo, measurement of a casein mRNA level was determined to evaluate the cytotoxic effects of TTO on BMECs. Our result demonstrated that $0.05 \%$ TTO did not have a profound alter in all experimental groups. Besides, addition of TTO can reduce the $S$. aureus growth, S. aureus biofilm formation and $S$. aureus invasion of BMECs. These result indicates that TTO may be beneficial for prophylactic mastitis and anti-inflammatory and is likely to be safe for in vivo use in bovine.

\section{Conclusions}

The present study indicates that $0.025 \%$ and $0.05 \%$ concentration of TTO increased the proliferation of BMECs, and enhanced the viability of BMECs exposed to S. aureus. BMECs incubated with TTO can relieve the inflammatory responses triggered by $S$. aureus, and enhance IL-8 expression to recruit the PMNL to mammary gland to mount the innate immune response of BMECs and PMNL. Importantly, TTO did not affect the expression of $\mathrm{k}$-casein in $S$. aureus-exposed BMECs. Therefore, TTO should be further considered for use as a novel therapy strategy for the bovine mastitis caused by S. aureus, to improve milk production and quality.

\section{Abbreviations \\ BMECs: Bovine mammary epithelial cells; FBS: Fetal bovine serum; GAPDH: Glyceraldehyde-3-phosphate dehydrogenase; IRAK1: Interleukin 1 receptor associated kinase 1; NFKBIA: NFKB inhibitor alpha; PMNL: Polymorphonuclear leukocy; S. aureus: Staphylococcus aureus; SOD2: Superoxide dismutase 2; TLR-2: Toll like receptor 2; TLR-4: Toll like receptor 4; TRAF6: TNF receptor associated factor 6; TTO: Tea tree oil}

\section{Acknowledgments}

We acknowledge Wuxi Chenfang Biotechnology Co., Ltd. for the TTO extract.

\section{Authors' contributions}

ZK performed experiment work, analyzed the data, and wrote the manuscript. YTY and FBB also performed experiment work. CYY revised the manuscript. ZXY and HYJ provide the support of TTO extract. Professor ZGQ contributes to the experimental idea. The authors read and approved the final manuscript.

\section{Funding}

This study was supported by the Research Project of Natural Science Foundation of Jiangsu Province (SBK2019043455), the National Natural Science Foundation of China (No. 31972589), China Agriculture Research System (CARS-36), and Development Project of China (2017YFD0502104-3).

\section{Availability of data and materials}

All data generated or analysed during this study are available from the corresponding author by request. The datasets supporting the conclusions of this article are included in the article.
Ethics approval and consent to participate

The experiments were approved by the Institutional Animal Care and Use Committee of Yang Zhou University.

\section{Consent for publication}

Not applicable.

\section{Competing interests}

The authors declare that they have no competing interests.

\section{Author details}

${ }^{1}$ Institute of Animal Culture Collection and Application, College of Animal Science and Technology, Yangzhou University, Yangzhou 225009, China.

${ }^{2}$ Wuxi Chenfang Biotechnology Co., Ltd., Wuxi, China.

Received: 19 September 2019 Accepted: 1 May 2020

Published online: 15 June 2020

\section{References}

1. Thompson-Crispi K, Atalla H, Miglior F, Mallard BA. Bovine mastitis: frontiers in immunogenetics. Front Immunol. 2014;5:493.

2. Bar D, Tauer LW, Bennett G, Gonzalez RN, Hertl JA, Schukken YH, et al. The cost of generic clinical mastitis in dairy cows as estimated by using dynamic programming. J Dairy Sci. 2008;91:2205-14.

3. Nickerson SC, Oliver SP. REVIEW: how well have United States dairy producers adopted mastitis-control technologies for reducing herd somatic cell counts improving milk quality? Prof Anim Sci. 2014;30:115-24.

4. Barlow J. Mastitis therapy and antimicrobial susceptibility: a multispecies review with a focus on antibiotic treatment of mastitis in dairy cattle. J Mammary Gland Biol Neoplasia. 2011;16:383-407.

5. Moser A, Stephan R, Corti S, Johler S. Comparison of genomic and antimicrobial resistance features of latex agglutination test-positive and latex agglutination test-negative Staphylococcus aureus isolates causing bovine mastitis. J Dairy Sci. 2013;96:329-34.

6. Li M, Du X, Villaruz AE, Diep BA, Wang D, Song Y, et al. MRSA epidemic linked to a quickly spreading colonization and virulence determinant. Nat Med. 2012;18:816-9.

7. Devriese LA, Damme LRV, Fameree L. Methicillin (cloxacillin)-resistant Staphylococcus aureus strains isolated from bovine mastitis cases. Zentralb| Veterinarmed B. 1972. p. 19598-605.

8. Bhattacharyya D, Banerjee J, Bandyopadhyay S, Mondal B, Nanda PK, Samanta I, et al. First report on vancomycin-resistant Staphylococcus aureus in bovine and caprine Milk. Microb Drug Resist. 2016;22:675-81.

9. Sol J, Sampimon OC, Barkema HW, Schukken YH. Factors associated with cure after therapy of clinical mastitis caused by Staphylococcus aureus. J Dairy Sci. 2000;83:278-84.

10. Federman C, Joo J, Almario JA, Salaheen S, Biswas D. Citrus-derived oil inhibits Staphylococcus aureus growth and alters its interactions with bovine mammary cells. J Dairy Sci. 2016;99:3667-74.

11. Kilani S, Ben SM, Limem I, Bouhlel I, Boubaker J, Bhouri W, et al. In vitro evaluation of antibacterial, antioxidant, cytotoxic and apoptotic activities of the tubers infusion and extracts of Cyperus rotundus. Bioresour Technol. 2008;99:9004-8.

12. Low WL, Martin C, Hill DJ, Kenward MA. Antimicrobial efficacy of liposomeencapsulated silver ions and tea tree oil against Pseudomonas aeruginosa, Staphylococcus aureus and Candida albicans. Lett Appl Microbiol. 2013;57: 33-9.

13. Sailer R, Berger T, Reichling J, Harkenthal M. Pharmaceutical and medicinal aspects of Australian tea tree oil. Phyton. 1998;5:489-95.

14. Carson CF, Hammer KA, Riley TV. Melaleuca alternifolia (tea tree) oil: a review of antimicrobial and other medicinal properties. Clin Microbiol Rev. 2006:19:50-62.

15. Cuaron JA, Dulal S, Song Y, Singh AK, Montelongo CE, Yu W, et al. Tea tree oil-induced transcriptional alterations in Staphylococcus aureus. Phytother Res. 2013:27:390-6.

16. Carvajal AM, Huircan P, Lepori A. Single nucleotide polymorphisms in immunity-related genes and their association with mastitis in Chilean dairy cattle. Genet Mol Res. 2013;12:2702-11.

17. Beecher CDM, Ross RP, Flynn J, McCarthy TV, Giblin L. Characterization of the bovine innate immune response in milk somatic cells following 
intramammary infection with Streptococcus dysgalactiae subspecies dysgalactiae. J Dairy Sci. 2012;95:5720-9.

18. Burvenich C, Bannerman DD, Lippolis JD, Peelman L, Nonnecke BJ, Kehrli $M E$, et al. Cumulative physiological events influence the inflammatory response of the bovine udder to Escherichia coli infections during the transition period. J Dairy Sci. 2007;90(Suppl 1):E39-54.

19. Garcia M, Elsasser TH, Biswas D, Moyes KM. The effect of citrus-derived oil on bovine blood neutrophil function and gene expression in vitro. J Dairy Sci. 2015;98:918-26.

20. Gong XX, Su XS, Zhan K, Zhao GQ. The protective effect of chlorogenic acid on bovine mammary epithelial cells and neutrophil function. J Dairy Sci. 2018;101:10089-97.

21. Qian C, Cao X. Regulation of toll-like receptor signaling pathways in innate immune responses. Ann N Y Acad Sci. 2013;1283:67-74.

22. Mitterhuemer S, Petzl W, Krebs S, Mehne D, Klanner A, Wolf E, Zerbe H, Blum H. Escherichia coli infection induces distinct local and systemic transcriptome responses in the mammary gland. BMC Genomics. 2010;11:138.

23. Petzl W, Zerbe H, Gunther J, Seyfert HM, Hussen J, Schuberth HJ. Pathogenspecific responses in the bovine udder. Models and immunoprophylactic concepts. Res Vet Sci. 2018;116:55-61.

24. Kerro Dego O, van Dijk JE, Nederbragt $\mathrm{H}$. Factors involved in the early pathogenesis of bovine Staphylococcus aureus mastitis with emphasis on bacterial adhesion and invasion-a review. Vet Q. 2002;24(4):181-98.

25. Barkema HW, Schukken YH, Zadoks RN. Invited review: the role of cow, pathogen, and treatment regimen in the therapeutic success of bovine Staphylococcus aureus mastitis. J Dairy Sci. 2006;89(6):1877-95.

26. Bazargani MM, Rohloff J. Antibiofilm activity of essential oils and plant extracts against Staphylococcus aureus and Escherichia coli biofilms. Food Control. 2016;61:156-64.

27. Lindsay $D$, von Holy A. Bacterial biofilms within the clinical setting: what healthcare professionals should know. J Hosp Infect. 2006;64(4):313-25.

28. Teixeira PC, Leite GM, Domingues RJ, Silva J, Gibbs PA, Ferreira JP. Antimicrobial effects of a microemulsion and a nanoemulsion on enteric and other pathogens and biofilms. Int J Food Microbiol. 2007;118(1):15-9.

29. Bozzuto G, Colone M, Toccacieli L, Stringaro A, Molinari A. Tea tree oil might combat melanoma. Planta Med. 2011;77:54-6.

30. Paape MJ, Bannerman DD, Zhao X, Lee JW. The bovine neutrophil: structure and function in blood and milk. Vet Res. 2003;34:597-627.

31. Kehrli ME Jr, Shuster DE. Factors affecting milk somatic cells and their role in health of the bovine mammary gland. J Dairy Sci. 1994;77:619-27.

32. Dinarello CA. Proinflammatory cytokines. Chest. 2000;118:503-8.

33. Prince LR, Whyte MK, Sabroe I, Parker LC. The role of TLRs in neutrophil activation. Curr Opin Pharmacol. 2011;11:397-403.

34. Smith-Palmer A, Stewart J, Fyfe L. Antimicrobial properties of plant essential oils and essences against five important food-borne pathogens. Lett Appl Microbiol. 1998;26:118-22.

Ready to submit your research? Choose BMC and benefit from:

- fast, convenient online submission

- thorough peer review by experienced researchers in your field

- rapid publication on acceptance

- support for research data, including large and complex data types

- gold Open Access which fosters wider collaboration and increased citations

- maximum visibility for your research: over $100 \mathrm{M}$ website views per year

At BMC, research is always in progress.

Learn more biomedcentral.com/submissions 